\title{
Clinicopathologic, Immunohistochemical, and Ultrastructural Findings of a Fatal Case of Middle East Respiratory Syndrome Coronavirus Infection in the United Arab Emirates, April 2014
}

Dianna L. Ng, ${ }^{*}$ Farida Al Hosani, ${ }^{\prime}$ M. Kelly Keating, ${ }^{*}$ Susan I. Gerber, ${ }^{\ddagger}$ Tara L. Jones, ${ }^{*}$ Maureen G. Metcalfe, ${ }^{*}$ Suxiang Tong, Ying Tao, ${ }^{\S}$ Negar N. Alami, ${ }^{\mathbb{T} \|}$ Lia M. Haynes, ${ }^{* *}$ Mowafaq Ali Mutei, ${ }^{\dagger \dagger}$ Laila Abdel-Wareth, ${ }^{\ddagger}$ Timothy M. Uyeki, ${ }^{\S}$ David L. Swerdlow, "ศึ Maha Barakat, ${ }^{\|\|}$and Sherif R. Zaki*

Accepted for publication

October 30, 2015.

Address correspondence to Sherif R. Zaki, M.D., Ph.D., Infectious Diseases Pathology Branch, Centers for Disease Control and Prevention, 1600 Clifton Rd., NE, Bldg. 18-SB130, Mail Stop G-32, Atlanta, GA 30329-4027. E-mail: szaki@cdc.gov.

\begin{abstract}
Middle East respiratory syndrome coronavirus (MERS-CoV) infection causes an acute respiratory illness and is associated with a high case fatality rate; however, the pathogenesis of severe and fatal MERS-CoV infection is unknown. We describe the histopathologic, immunohistochemical, and ultrastructural findings from the first autopsy performed on a fatal case of MERS-CoV in the world, which was related to a hospital outbreak in the United Arab Emirates in April 2014. The main histopathologic finding in the lungs was diffuse alveolar damage. Evidence of chronic disease, including severe peripheral vascular disease, patchy cardiac fibrosis, and hepatic steatosis, was noted in the other organs. Double staining immunoassays that used anti-MERS-CoV antibodies paired with immunohistochemistry for cytokeratin and surfactant identified pneumocytes and epithelial syncytial cells as important targets of MERS-CoV antigen; double immunostaining with dipeptidyl peptidase 4 showed colocalization in scattered pneumocytes and syncytial cells. No evidence of extrapulmonary MERS-CoV antigens were detected, including the kidney. These results provide critical insights into the pathogenesis of MERS-CoV in humans. (Am J Pathol 2016, 186: 652-658; http://dx.doi.org/10.1016/j.ajpath.2015.10.024)
\end{abstract}

Middle East respiratory syndrome coronavirus (MERS$\mathrm{CoV}$ ) was initially isolated from a sputum specimen of a patient who died of respiratory and renal failure in Saudi Arabia in 2012. ${ }^{1}$ Recent data have indicated that dromedary camels are likely to transmit MERS-CoV to humans. ${ }^{2,3}$ Human-to-human MERS-CoV transmission is well documented, particularly in the setting of nosocomial outbreaks. $^{4,5}$

As of July 7, 2015, the World Health Organization (WHO) was notified of 1368 laboratory-confirmed cases of MERS-CoV infection with 487 reported deaths (35.6\%) from 26 countries, primarily in men with a median age of 50 years. $^{6}$ Most cases $(>75 \%)$ were reported from the Kingdom of Saudi Arabia. ${ }^{6}$ MERS-CoV infection can result in a wide clinical spectrum from asymptomatic infection, upper respiratory tract illness, to severe pneumonia and multiorgan failure. ${ }^{7-9}$ MERS-CoV binds to dipeptidyl

\footnotetext{
Supported by CDC operational funds

The findings and conclusions in this report are those of the authors and do not necessarily represent the official position of the CDC.

Disclosures: None reported.

Current address of M.G.M., National Cancer Institute-Shady Grove, Rockville, MD.
} 
Table 1 Primary Antibodies Used for IHC

\begin{tabular}{|c|c|c|c|c|c|c|c|}
\hline Ab No. & Primary Ab & Host & Dilution & Pretreatment & Ab source & Detection & Comments \\
\hline 1510/1513 & MERS-CoV & $\begin{array}{l}\text { Mouse hyperimmune } \\
\text { serum }\end{array}$ & $1: 200$ & PK & $C D C, D V D$ & (no. 1253) UVLP & $\begin{array}{l}\text { MERS-CoV } \\
\text { JordanN3 }\end{array}$ \\
\hline 1512 & HKU5.2 N & $\begin{array}{l}\text { Mouse hyperimmune } \\
\text { serum }\end{array}$ & $1: 500$ & AR & $C D C, D V D$ & (no. 1253) UVLP & Bat coronavirus \\
\hline 0274 & CD68 (KP1) & MAB & $1: 100$ & AR & Dako & $\begin{array}{l}\text { (no. 1371) Envision } \\
\text { Doublestain }\end{array}$ & \\
\hline 0304 & $\begin{array}{l}\text { Cytokeratin (AE1 and } \\
\text { AE3) }\end{array}$ & MAB & $1: 100$ & AR & Dako & $\begin{array}{l}\text { (no. 1371) Envision } \\
\text { Doublestain }\end{array}$ & \\
\hline 1037 & $\begin{array}{l}\text { Surfactant apoprotein } \\
\text { A (PE10) }\end{array}$ & HMAF & $1: 100$ & AR & Dako & $\begin{array}{l}\text { (no. 1371) Envision } \\
\text { Doublestain }\end{array}$ & \\
\hline
\end{tabular}

Ab, antibody; AR, antigen retrieval; DPP4, dipeptidyl peptidase 4; DVD, Division of Viral Diseases (CDC); EMC S, spike protein of human coronavirus Erasmus Medical Center; Envision Doublestain, Envision G/2 Double Stain System, Rabbit/Mouse (DAB + Permanent Red); HKU5.2 N, bat coronavirus HKU5.2 nucleoprotein; HMAF, hyperimmune mouse ascitic fluid; Klear, Klear Human AP-Polymer Detection Kit with GBI Permanent Red Chromogen; MAB, monoclonal antibody; MERS-CoV, Middle East respiratory syndrome coronavirus; PK, proteinase K; UNC, University of North Carolina; UVLP, UltraVision Labeled Polymer Detection Kit.

peptidase 4 (DPP4) receptors that are primarily in the lower respiratory tract but also distributed in other tissues. ${ }^{10}$ Although there have been numerous cases and fatalities, the pathologic changes and viral distribution in humans associated with severe MERS-CoV illness are unknown, and knowledge of pathogenesis remains limited.

This report provides the first autopsy, clinicopathologic, immunohistochemical (IHC), and ultrastructural description of a fatal case of MERS-CoV. This patient, who had multiple close contacts, was identified as part of an epidemiologic investigation of a large cluster of MERS-CoV infections at hospital in the United Arab Emirates (UAE) in April 2014. This outbreak occurred in the context of a surge of cases in the Arabian Peninsula in which 515 MERS-CoV cases were identified in Saudi Arabia from April 11 to June 9, 2014 (World Health Organization, http://www.who.int/csr/don/2014_06_13_ mers/en, last accessed October 9, 2015).

\section{Materials and Methods}

\section{Histopathologic and IHC Studies}

Tissues obtained at autopsy were fixed in $10 \%$ buffered formalin, paraffin-embedded, sectioned at $4 \mu \mathrm{m}$, and stained by routine hematoxylin and eosin. An immunostaining protocol was applied with use of several mouse antibodies and one human antibody to MERS-CoV as described previously. ${ }^{11}$

IHC assays that used mouse anti-MERS antibodies (Table 1) were performed with the use of a polymer-based indirect immunoalkaline phosphatase detection system with colorimetric detection of antibody/polymer complex with Fast Red Chromogen (Thermo Fisher Scientific, Runcom, Cheshire, UK, or Biocare Medical, Concord, CA). IHC assays with the use of the human, anti-MERS-CoV antibody were performed with the Klear Human AP-Polymer Detection Kit with GBI Permanent Red Chromogen (GBI Labs, Bothell, WA). Double-stained assays used the Envision G/2 Double Stain System, Rabbit/Mouse (DAB + Permanent Red) from Dako (Glostrup, Denmark). Antibodies against CD68 (Dako), cytokeratin (Dako), surfactant apoprotein A (Dako), and DPP4 (Origene Technologies, Rockville, MD), followed by the anti-MERS-CoV antibodies [CDC (Atlanta, GA) and University of North Carolina (Chapel Hill, NC)], were used. All assays were performed according to the manufacturer's guidelines. MERSCoV-infected and -noninfected Vero cells and tissues from non-MERS-CoV cases and normal mouse sera in place of primary antibodies were used as positive and negative controls, respectively.

\section{Ultrastructural Studies}

Lung tissue samples were excised from a paraffin block with the use of a 2-mm punch and processed for electron microscopy examination as previously described. ${ }^{12}$

\section{Molecular Analysis}

Full genome sequencing by the Sanger method with the use of direct genome walking PCR and next-generation sequencing (Illumina MiSeq; Illumina, San Diego, CA) were performed as previously described on confirmed positive lung tissue, ${ }^{13}$ named as Abu Dhabi_UAE_8_2014 and deposited into GenBank (http://www.ncbi.nlm.nih.gov; GenBank accession number KP209306). ClustalW was used to align the full genome with the respective available complete or near complete MERS-CoV genomes in 

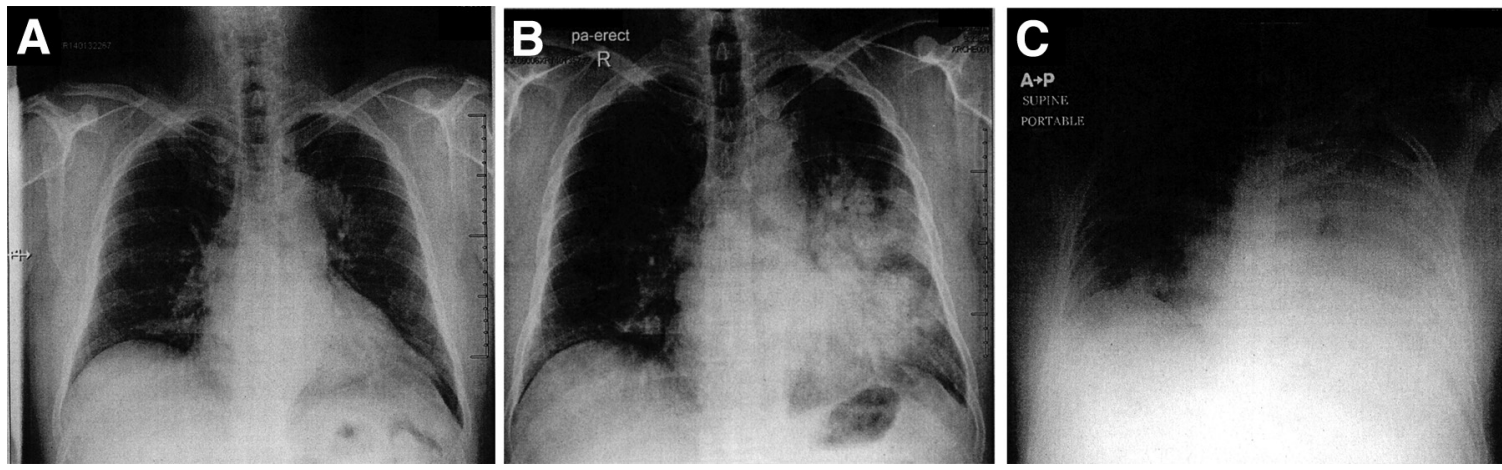

Figure 1 CXR images. A: CXR at initial ED visit shows small left-sided opacity. B: CXR at second ED visit, with increase of left-sided opacity. C: Portable CXR 1 day after admission with substantial progression of the opacity. CXR, chest X-ray; ED, emergency department.

GenBank. ${ }^{14}$ Phylogenetic reconstructions were performed with MrBayes version 3.2 (MrBayes: Bayesian Inference of Phylogeny, http://mrbayes.sourceforge.net, last accessed June 22, 2015) under a General-Time-Reversible model of nucleotide substitution with four categories of $\gamma$-distributed rate heterogeneity and a proportion of invariant sites $(\mathrm{GTR}+4+\mathrm{I}) .^{15}$

\section{Results}

\section{Clinical History and Findings}

The patient was a 45-year-old, nonsmoking, obese (body mass index, $30.5 \mathrm{~kg} / \mathrm{m}^{2}$ ) Filipino man with no relevant past medical history, recent travel, or exposure to sick contacts or farm animals. He worked in a storage room at a paramedic station with no patient care duties. He shared housing with five roommates from the paramedic department.

He presented to an emergency department in Abu Dhabi, UAE, on April 2, 2014, with a 4-day history of fever, rhinorrhea, and productive cough. At evaluation, he was afebrile with an oxygen saturation of $99 \%$ on room air, and a chest X-ray showed a left-sided opacity (Figure 1A). The patient was diagnosed as acute bronchitis, prescribed $20 \mathrm{mg}$ prednisolone daily for 5 days and paracetamol, and discharged. He returned to the emergency department on April 6, 2014, with persistent cough and shortness of breath; a chest X-ray showed a left-sided opacity and air bronchograms, and the patient was diagnosed with pneumonia, given a prescription for levofloxacin, and discharged (Figure 1B). He returned to the emergency department the same day, with worsening shortness of breath and was admitted. He had a temperature of $38.7^{\circ} \mathrm{C}$, pulse of 113 beats per minute, a respiratory rate of 24 breaths per minute, blood pressure of 123/73, an oxygen saturation of $93 \%$ on room air, and left basal crackles and rales. An arterial blood gas on room air showed $\mathrm{pH}$ of 7.49 , partial pressure of carbon dioxide of $27.6 \mathrm{~mm} \mathrm{Hg}$, partial pressure of oxygen of $52.4 \mathrm{~mm} \mathrm{Hg}$, and bicarbonate of $20.7 \mathrm{mEq} / \mathrm{L}$, consistent with respiratory alkalosis. Laboratory evaluation showed a normal white blood cell count with lymphopenia $(0.5 \mathrm{~K} / \mu \mathrm{L})$ and creatinine of $0.9 \mathrm{mg} / \mathrm{dL}$ (Supplemental Table S1). Blood, sputum, and urine cultures were obtained, and a nasopharyngeal swab specimen was sent for MERS-CoV testing. On April 7, day 1 of admission, oseltamivir, ceftriaxone, and azithromycin were started empirically. The day after admission he was transferred to the intensive care unit for tachypnea and respiratory distress and was intubated for mechanical ventilation; a portable chest X-ray showed multiple patchy airspace opacities (Figure 1C). The patient became hypotensive, requiring inotropic support, and developed acute kidney injury and renal failure, requiring dialysis. On April 8, RT-PCR assay of the nasopharyngeal swab specimen collected on April 7 was reported to be positive for MERS-CoV for UpE and ORF1a gene targets. ${ }^{16}$ Bacterial cultures of blood, sputum, and urine specimens obtained at admission after antibiotic administration were negative. On April 9, he was given $100 \mathrm{mg}$ hydrocortisone intravenously every 8 hours and started on nitric oxide at $16 \mathrm{ppm}$. The patient's condition continued to deteriorate, and he died April 10.

\section{Autopsy}

The body was kept refrigerated at $4^{\circ} \mathrm{C}$, and an autopsy was performed 10 days after death. Notable findings included massive pleural effusion ( $5 \mathrm{~L}$ ), substantial pericardial effusion $(150 \mathrm{~mL})$, and abdominal effusion; edematous and consolidated lungs; and generalized congestion.

\section{Histopathology, Immunohistochemistry, and Electron Microscopy}

The predominant pulmonary histologic pattern was exudative-phase diffuse alveolar damage with denuding of bronchiolar epithelium, prominent hyaline membranes, alveolar fibrin deposits, type 2 pneumocyte hyperplasia, rare multinucleated syncytial cells, and alveolar septa involved by edema and lymphocytes with fewer plasma cells, neutrophils, and macrophages (Figure 2, A-C). Dispersed foci of necrotic debris were seen both subpleurally and within alveoli. No viral inclusions were seen, and moderate anthracosis was present. All four antibodies (1510/1513, 

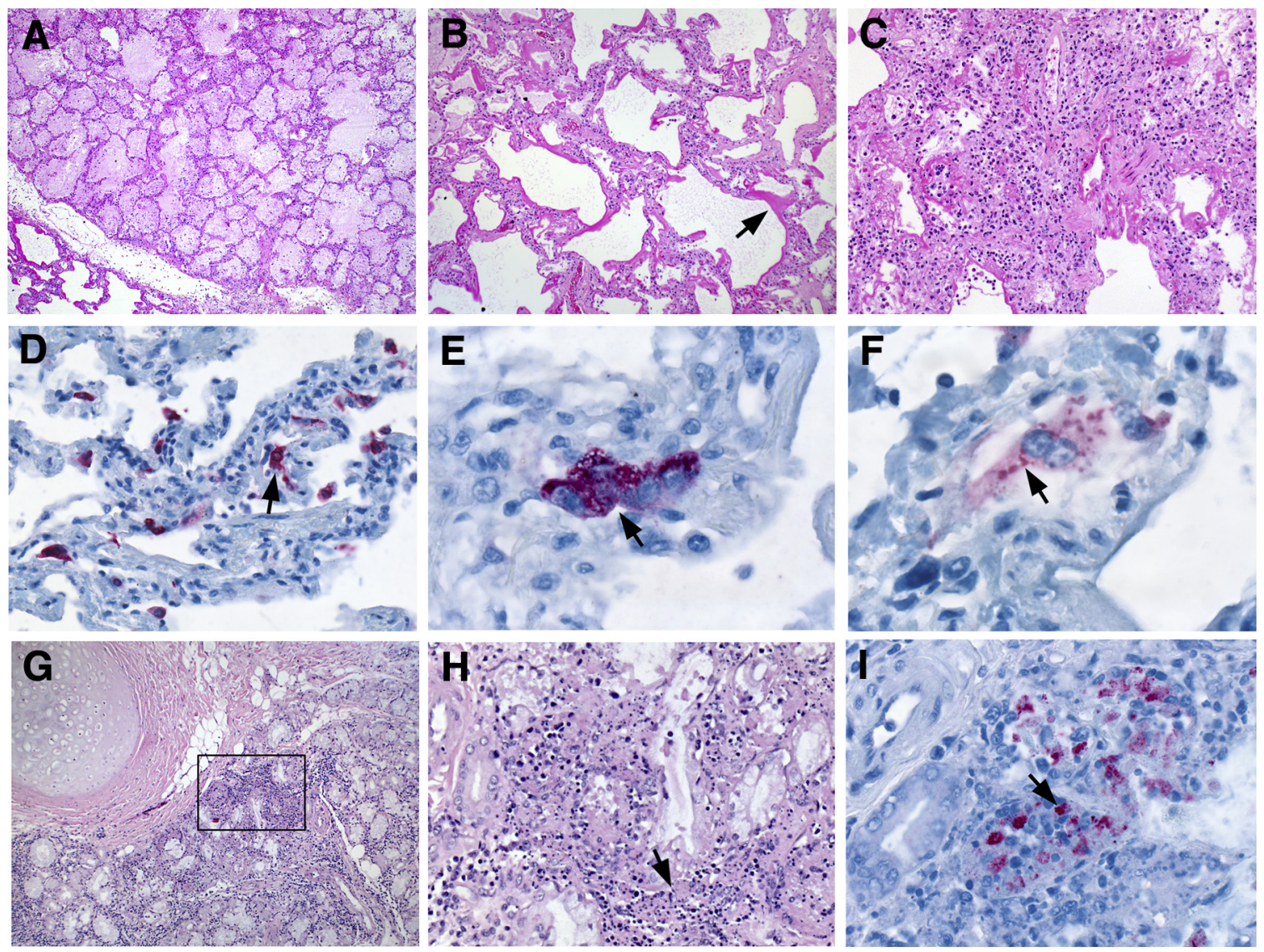

Figure 2 Histopathology of lung from MERS-CoV patient. A: Pulmonary edema. B: Diffuse alveolar damage, including prominent hyaline membrane formation (arrow). C: Alveolar fibrin deposits, type 2 pneumocyte hyperplasia, and thickened alveolar septa involved by edema and a mixed inflammatory infiltrate. D-F: Immunostaining of MERS-CoV antigen in pneumocytes (Ab 1511; D, arrow), a multinucleated syncytial cell (Ab 1511; E, arrow), and a binucleated cell (Ab 1514; F, arrow). G: Moderate lymphocytic inflammation of the submucosal glands. H: Magnified from the boxed area in G. Submucosal glands with focal areas of necrosis (arrow). I: Immunostaining of MERS-CoV antigen in necrotic foci of submucosal glands (arrow; Ab 1512). Original magnification: $\times 5(\mathbf{A}) ; \times 20(\mathbf{B}-\mathbf{D}) ; \times 75(\mathbf{E}) ; \times 100(\mathbf{F}) ; \times 10(\mathbf{G}) ; \times 40(\mathbf{H}) ; \times 63(\mathbf{I})$. Ab, antibody; MERS-CoV, Middle East respiratory syndrome coronavirus.

1511, 1512, and 1514) highlighted multiple foci of MERS$\mathrm{CoV}$ antigens, predominantly localized within the cytoplasm of pneumocytes and syncytial cells (Figure 2, D-F). Sections of trachea and bronchi showed mild-to-moderate lymphocytic mucosal and submucosal inflammation with a few neutrophils and plasma cells (Figure 2G). Occasional clusters of noninvasive and extracellular candida yeast and hyphae were seen in septa, alveolar spaces, and overlying respiratory epithelium, suggesting postmortem overgrowth. Bronchial submucosal glands were focally necrotic (Figure 2H). Immunostaining for MERS-CoV antigens was identified in both unremarkable and necrotic bronchial submucosal glands (Figure 2I).

Multiple double immunostaining immunoassays were performed to assess for colocalization of MERS-CoV and cells labeling for cytokeratin, CD68, surfactant, and DPP4. Double staining with cytokeratin confirmed the presence of viral antigens within pneumocytes and epithelial syncytial cells, whereas double staining with CD68 showed two distinct populations with no colocalization of MERS-CoV and macrophages (Figure 3, A and B). Surfactant double staining revealed type 2 pneumocytes and syncytial cells with intracytoplasmic viral antigens (Figure 3C). DPP4 antigens were detected in pneumocytes, syncytial cells, mononuclear leukocytes, and vascular endothelium, although colocalization of MERS-CoV and DPP4 was observed in scattered pneumocytes and syncytial cells (Figure 3D). Electron microscopy showed infected and degenerated pneumocytes encased between hyaline membranes, composed of fibrin and basement membranes (Figure 3E). Clusters or individualized, predominately spherical, 50 to $150 \mathrm{~nm}$ in diameter, viral particles were observed in membrane-bound vesicles (Figure 3F).

The kidney showed increased globally sclerotic glomeruli (5\% to $10 \%$ of glomeruli), thickened Bowman capsules, severe atherosclerosis and hyaline arteriolosclerosis, patchy interstitial inflammation, and intratubular proteinaceous and granular casts. Diminished lymphoid follicles and a robust interfollicular proliferation of pleomorphic immunoblasts intermixed with a polymorphous population of reactive lymphocytes were seen in multiple lymph nodes; the spleen also contained numerous immunoblasts and reactive lymphocytes. The bone marrow was normocellular with maturing trilineage hematopoiesis and left-shifted 

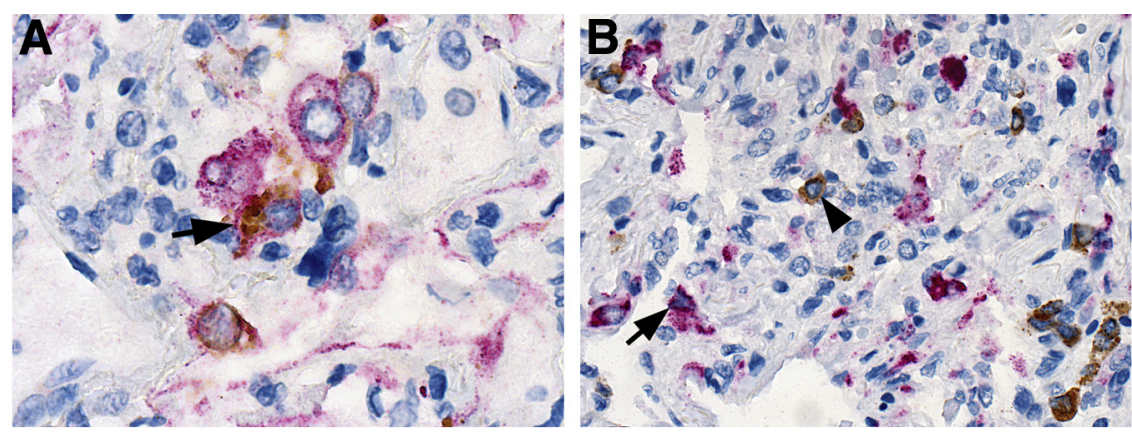

Figure 3 Immunohistochemical and ultrastructural localization of MERS-CoV and associated histologic findings. A: MERS-CoV and cytokeratin antigens in pneumocytes (arrow); red stain, MERS-CoV; brown stain, cytokeratin. B: MERS-CoV antigens in pneumocytes (arrowhead) and CD68 antigens in macrophages (arrow); red stain, CD68; brown stain, MERS-CoV. C: MERS-CoV and surfactant antigens in type 2 pneumocytes (arrow); red stain, surfactant; brown stain, MERS-CoV. D: MERS-CoV and DPP4 in pneumocytes (arrow); red stain, DPP4; brown stain, MERS-CoV. E: Fragmented pneumocyte infected with MERS-CoV, hyaline membrane (arrowhead) present. F: Magnified from the boxed area in E. MERS-CoV virions dispersed as single particles (arrow) or in clusters within membrane-bound vesicles (arrowhead). Spherical and pleomorphic particles ranged in size from 50 to $150 \mathrm{~nm}$ diameter. Scale bars: $2 \mu \mathrm{m}(\mathbf{E})$; $500 \mathrm{~nm}(\mathbf{F})$. Original magnification: $\times 100($ A and C); $\times 63($ B $) ; \times 75$ (D). DPP4, dipeptidyl peptidase 4; MERS-CoV, Middle East respiratory syndrome coronavirus.
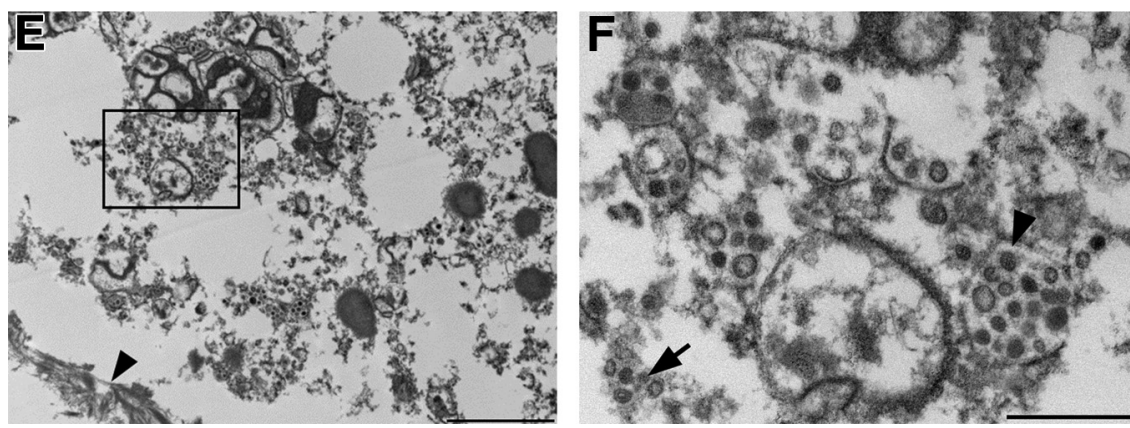

granulopoiesis. The heart revealed diffuse myocyte hypertrophy, moderate coronary atherosclerosis, and patchy fibrosis. Moderate steatosis, scattered calcifications, and mild portal tract and lobular lymphocytic inflammation were identified in the liver. The sections of the cerebrum and cerebellum were unremarkable. MERS-CoV IHC was negative in multiple specimens from different organs, including kidney, liver, spleen, several lymph nodes, bone marrow, small intestine, and colon.

Overall the histology was well-preserved; although the sections of brain showed minimal-to-mild autolysis and kidney showed moderate autolysis.

\section{Molecular Assays}

The genome sequence is similar $(>99 \%)$ to other known MERS-CoVs and clustered closely with camel-derived MERS-CoV strains (KJ650295 to KJ650297) obtained in Al-Hasa, Saudi Arabia, in 2013, suggesting recent origin in camels, although the patient had no known camel exposures. As indicated from the phylogenetic tree (Supplemental Figure S1), the sequences from this case and close contacts cluster most closely in the same clade, further supporting their transmission link between these cases.

\section{Discussion}

This report provides invaluable insights as the first description in the published literature of the clinicopathologic, IHC, and ultrastructural findings of a fatal case of MERS-CoV infection. The histopathologic pattern observed in the lungs was diffuse alveolar damage. MERS-CoV IHC and double staining techniques showed viral antigens were predominantly localized to type 2 pneumocytes and epithelial syncytial cells. Although the pathogenesis of severe and fatal MERS-CoV infection is unknown, these postmortem findings provide critical insights, including evidence that pneumocytes are important targets, suggesting that direct cytopathic effects contribute to MERSCoV respiratory symptoms. An ex vivo study that examined MERS-CoV-infected human lung tissue found evidence of pneumocyte damage by electron microscopy, including detachment of type 2 pneumocytes, and membrane blebbing, suggestive of apoptosis. ${ }^{17}$ However, IHC staining for MERS$\mathrm{CoV}$ was patchy, implying that other causes such as immune dysfunction may be relevant. Acute renal failure is commonly 
observed in critically ill MERS-CoV patients $^{7-9,18}$ and MERS-CoV RNA was detected in urine ${ }^{18,19}$; however, no evidence of extrapulmonary MERS-CoV dissemination was observed, suggesting that acute renal failure in this patient was not caused by direct renal infection but likely by other factors, such as hypoperfusion or cytokine dysregulation. The presence of MERS-CoV antigens in submucosal glands provides a mechanism by which the virus enters respiratory secretions and becomes transmissible.

The pathologic features of MERS-CoV are shared by other similar respiratory illnesses, such as severe acute respiratory syndrome (SARS)-CoV. Several reports that evaluated fatal cases of SARS-CoV describe diffuse alveolar damage in various stages as the most characteristic feature, ${ }^{20}$ with IHC staining of SARS-CoV antigen primarily in alveolar epithelial cells. ${ }^{20}$ Syncytial cells may also be seen with other coronavirus infections, including SARS$\mathrm{CoV}$ and paramyxovirus infections. ${ }^{20}$ MERS-CoV entry is mediated by DPP4, which is expressed throughout the lower respiratory tract ${ }^{17}$ but also numerous other organs, including the kidney. ${ }^{10}$ Double staining with MERS-CoV and DPP4 IHC was seen in pneumocytes and syncytial cells, consistent with the identification of these cells as targets of MERS$\mathrm{CoV}$ infection. In addition, ex vivo models have detected MERS-CoV antigen in bronchial epithelial cells, pneumocytes, and endothelium and DPP4 in bronchiolar epithelium, endothelium, pneumocytes, and alveolar macrophages, ${ }^{17,21}$ correlating with our findings. In contrast, the functional receptor for SARS-CoV is angiotensin-converting enzyme $2 .^{22}$ Similar to DDP4, angiotensin-converting enzyme 2 has a broad distribution, with heavy expression in alveolar epithelial cells, enterocytes, and endothelial cells. ${ }^{23}$ Although evidence shows that SARS-CoV also infects type 2 pneumocytes, ${ }^{24,25}$ SARS-CoV was detected in several extrapulmonary sites by in situ hybridization and electron microscopy, including circulating lymphocytes, lymphoid tissues, renal distal tubules, and small intestinal mucosa. ${ }^{26}$ Because MERS-CoV RNA was detected in blood, ${ }^{19}$ and DPP4 is widely distributed in different tissues, ${ }^{10}$ extrapulmonary dissemination could be possible, but we did not detect any evidence of MERS-CoV spread outside the respiratory tract.

Pulmonary findings of consolidation, diffuse alveolar damage, and pleural effusions with no evidence of bacterial pneumonia are consistent with the clinical features reported in other critically ill adults with MERS-CoV infection. ${ }^{7-9}$ Pathologic evidence of several chronic diseases in this patient, including myocardial fibrosis, atherosclerosis, and hepatic steatosis, correlates with reports of individuals with underlying comorbidities, such as end-stage renal disease, diabetes mellitus, hypertension, or cardiac disease, having an increased risk of developing severe MERS-CoV infection. $^{4,7}$ The impact of low-dose oral prednisolone before admission and intravenous hydrocortisone on the clinical course and fatal outcome of this MERS-CoV patient is unknown. Follicular depletion in lymph nodes, consistent with corticosteroid use, was noted, and no bacterial coinfections were identified. The hydrocortisone dosing of 100 mg every 8 hours in the intensive care unit before death was higher than recommended for refractory septic shock by the Surviving Sepsis Campaign guidance, ${ }^{27}$ but the patient only received a few doses. A systematic review of high-dose corticosteroids for treatment of SARS-CoV reported evidence of harm without survival benefit. ${ }^{28}$ In patients with influenza $\mathrm{A}(\mathrm{H} 1 \mathrm{~N} 1) \mathrm{pdm} 09$ virus infection, corticosteroid treatment was associated with increased mortality, ${ }^{29}$ although further studies are needed. Therefore, until further evidence is available, high-dose corticosteroid treatment for MERS-CoV pulmonary disease should be avoided ${ }^{30}$ Current clinical management of MERS-CoV patients is based on supportive care of complications and adherence to recommended infection prevention and control measures (CDC, http://www.cdc.gov/coronavirus/mers/infection-preventioncontrol.html, last accessed October 9, 2015).

Our findings provide invaluable and unprecedented insights into the histologic changes, pathogenesis, and viral dissemination of MERS-CoV in humans. Further studies, including additional postmortem examinations, evaluation of the host immune response, and identification of sites of viral replication, are necessary to strengthen knowledge on pathogenesis, transmission patterns, and effective treatment strategies for optimal clinical management and infection control practices.

\section{Acknowledgments}

We thank Cynthia Goldsmith for reviewing the electron microscopy and Azaibi Tamin for providing the MERS$\mathrm{CoV}$-infected Vero cell cultures.

\section{Supplemental Data}

Supplemental material for this article can be found at http://dx.doi.org/10.1016/j.ajpath.2015.10.024.

\section{References}

1. Zaki AM, van Boheemen S, Bestebroer TM, Osterhaus AD, Fouchier RA: Isolation of a novel coronavirus from a man with pneumonia in Saudi Arabia. N Engl J Med 2012, 367:1814-1820

2. Azhar EI, El-Kafrawy SA, Farraj SA, Hassan AM, Al-Saeed MS, Hashem AM, Madani TA: Evidence for camel-to-human transmission of MERS coronavirus. N Engl J Med 2014, 370:2499-2505

3. Haagmans BL, Al Dhahiry SH, Reusken CB, Raj VS, Galiano M, Myers R, Godeke GJ, Jonges M, Farag E, Diab A, Ghobashy H, Alhajri F, Al-Thani M, Al-Marri SA, Al Romaihi HE, Al Khal A, Bermingham A, Osterhaus AD, AlHajri MM, Koopmans MP: Middle East respiratory syndrome coronavirus in dromedary camels: an outbreak investigation. Lancet Infect Dis 2014, 14:140-145

4. Assiri A, McGeer A, Perl TM, Price CS, Al Rabeeah AA, Cummings DA, Alabdullatif ZN, Assad M, Almulhim A, Makhdoom H, Madani H, Alhakeem R, Al-Tawfiq JA, Cotten M, Watson SJ, Kellam P, Zumla AI, Memish ZA; KSA MERS-CoV 
Investigation Team: Hospital outbreak of Middle East respiratory syndrome coronavirus. N Engl J Med 2013, 369:407-416

5. Al-Abdallat MM, Payne DC, Alqasrawi S, Rha B, Tohme RA, Abedi GR, Al Nsour M, Iblan I, Jarour N, Farag NH, Haddadin A, Al-Sanouri T, Tamin A, Harcourt JL, Kuhar DT, Swerdlow DL, Erdman DD, Pallansch MA, Haynes LM, Gerber SI; Jordan MERS$\mathrm{CoV}$ Investigation Team: Hospital-associated outbreak of Middle East respiratory syndrome coronavirus: a serologic, epidemiologic, and clinical description. Clin Infect Dis 2014, 59:1225-1233

6. World Health Organization: Middle East respiratory syndrome coronavirus (MERS-CoV-Summary of Current Situation. Lit Update Risk Assess 7 July 2015. Available at: http://www.who.int/csr/disease/ coronavirus_infections/risk-assessment-7july2015/en

7. Assiri A, Al-Tawfiq JA, Al-Rabeeah AA, Al-Rabiah FA, Al-Hajjar S, Al-Barrak A, Flemban H, Al-Nassir WN, Balkhy HH, Al-Hakeem RF, Makhdoom HQ, Zumla AI, Memish ZA: Epidemiological, demographic, and clinical characteristics of 47 cases of Middle East respiratory syndrome coronavirus disease from Saudi Arabia: a descriptive study. Lancet Infect Dis 2013, 13:752-761

8. Saad M, Omrani AS, Baig K, Bahloul A, Elzein F, Matin MA, Selim MA, Al Mutairi M, Al Nakhli D, Al Aidaroos AY, Al Sherbeeni N, Al-Khashan HI, Memish ZA, Albarrak AM: Clinical aspects and outcomes of 70 patients with Middle East respiratory syndrome coronavirus infection: a single-center experience in Saudi Arabia. Int J Infect Dis 2014, 29:301-306

9. Arabi YM, Arifi AA, Balkhy HH, Najm H, Aldawood AS, Ghabashi A, Hawa H, Alothman A, Khaldi A, Al Raiy B: Clinical course and outcomes of critically ill patients with Middle East respiratory syndrome coronavirus infection. Ann Intern Med 2014, 160: 389-397

10. Raj VS, Mou H, Smits SL, Dekkers DH, Müller MA, Dijkman R, Muth D, Demmers JA, Zaki A, Fouchier RA, Thiel V, Drosten C, Rottier PJ, Osterhaus AD, Bosch BJ, Haagmans BL: Dipeptidyl peptidase 4 is a functional receptor for the emerging human coronavirus-EMC. Nature 2013, 495:251-254

11. Engel RM, Morris M, Henning T, Ritter JM, Jones TL, Dietz S, Ayers J, Vishwanathan SA, Jenkins L, Zaki S, Wildemeersch D, Garber D, Powell N, Hendry RM, McNicholl J, Kersh EN: Evaluation of pigtail macaques as a model for the effects of copper intrauterine devices on HIV infection. J Med Primatol 2014, 43:349-359

12. Paddock CD, Sanden GN, Cherry JD, Gal AA, Langston C, Tatti KM, Wu KH, Goldsmith CS, Greer PW, Montague JL, Eliason MT, Holman RC, Guarner J, Shieh WJ, Zaki SR: Pathology and pathogenesis of fatal Bordetella pertussis infection in infants. Clin Infect Dis 2008, 47:328-338

13. Cotten M, Lam TT, Watson SJ, Palser AL, Petrova V, Grant P, Pybus OG, Rambaut A, Guan Y, Pillay D, Kellam P, Nastouli E: Fullgenome deep sequencing and phylogenetic analysis of novel human betacoronavirus. Emerg Infect Dis 2013, 19:736-742B

14. Larkin MA, Blackshields G, Brown NP, Chenna R, McGettigan PA, McWilliam $\mathrm{H}$, Valentin F, Wallace IM, Wilm A, Lopez $\mathrm{R}$, Thompson JD, Gibson TJ, Higgins DG: ClustalW and ClustalX version 2 (2007). Bioinformatics 2007, 23:2947-2948

15. Huelsenbeck JP, Ronquist F: MRBAYES: Bayesian inference of phylogenetic trees. Bioinformatics 2001, 17:754-755

16. Lu X, Whitaker B, Sakthivel SK, Kamili S, Rose LE, Lowe L, Mohareb E, Elassal EM, Al-sanouri T, Haddadin A, Erdman DD: Realtime reverse transcription-PCR assay panel for Middle East respiratory syndrome coronavirus. J Clin Microbiol 2014, 52:67-75

17. Hocke AC, Becher A, Knepper J, Peter A, Holland G, Tonnies M, Bauer TT, Schneider P, Neudecker J, Muth D, Wendtner CM, Ruckert JC, Drosten C, Gruber AD, Laue M, Suttorp N, Hippenstiel S, Wolff $\mathrm{T}$ : Emerging human middle East respiratory syndrome coronavirus causes widespread infection and alveolar damage in human lungs. Am J Respir Crit Care Med 2013, 188:882-886

18. Poissy J, Goffard A, Parmentier-Decrucq E, Favory R, Kauv M, Kipnis E, Mathieu D, van der Werf S, Guery B; MERS-CoV Biology Group: Kinetics and pattern of viral excretion in biological specimens of two MERS-CoV cases. J Clin Virol 2014, 61:275-278

19. Drosten C, Seilmaier M, Corman VM, Hartmann W, Scheible G, Sack S, Guggemos W, Kallies R, Muth D, Junglen S, Müller MA, Haas W, Guberina H, Röhnisch T, Schmid-Wendtner M, Aldabbagh S, Dittmer U, Gold H, Graf P, Bonin F, Rambaut A, Wendtner C: Clinical features and virological analysis of a case of Middle East respiratory syndrome coronavirus infection. Lancet Infect Dis 2013, 13:745-751

20. Nicholls JM, Butany J, Poon LL, Chan KH, Beh SL, Poutanen S, Peiris JS, Wong M: Time course and cellular localization of SARS$\mathrm{CoV}$ nucleoprotein and RNA in lungs from fatal cases of SARS. PLoS Med 2006, 3:e27

21. Chan RW, Hemida MG, Kayali G, Chu DK, Poon LL, Alnaeem A, Ali MA, Tao KP, Ng HY, Chan MC, Guan Y, Nicholls JM, Peiris JS: Tropism and replication of Middle East respiratory syndrome coronavirus from dromedary camels in the human respiratory tract: an invitro and ex-vivo study. Lancet Respir Med 2014, 2:813-822

22. Li W, Moore MJ, Vasilieva N, Sui J, Wong SK, Berne MA, Somasundaran M, Sullivan JL, Luzuriaga K, Greenough TC, Choe H, Farzan M: Angiotensin-converting enzyme 2 is a functional receptor for the SARS coronavirus. Nature 2003, 426:450-454

23. Hamming I, Timens W, Bulthuis ML, Lely AT, Navis G, van Goor H: Tissue distribution of ACE2 protein, the functional receptor for SARS coronavirus. A first step in understanding SARS pathogenesis. J Pathol 2004, 203:631-637

24. Mossel EC, Wang J, Jeffers S, Edeen KE, Wang S, Cosgrove GP, Funk CJ, Manzer R, Miura TA, Pearson LD, Holmes KV, Mason RJ: SARS-CoV replicates in primary human alveolar type II cell cultures but not in type I-like cells. Virology 2008, 372:127-135

25. Shieh WJ, Hsiao CH, Paddock CD, Guarner J, Goldsmith CS, Tatti K, Packard M, Mueller L, Wu MZ, Rollin P, Su IJ, Zaki SR: Immunohistochemical, in situ hybridization, and ultrastructural localization of SARS-associated coronavirus in lung of a fatal case of severe acute respiratory syndrome in Taiwan. Hum Pathol 2005, 36:303-309

26. Gu J, Gong E, Zhang B, Zheng J, Gao Z, Zhong Y, Zou W, Zhan J, Wang S, Xie Z, Zhuang H, Wu B, Zhong H, Shao H, Fang W, Gao D, Pei F, Li X, He Z, Xu D, Shi X, Anderson VM, Leong AS: Multiple organ infection and the pathogenesis of SARS. J Exp Med 2005, 202 : 415-424

27. Dellinger RP, Levy MM, Rhodes A, Annane D, Gerlach H, Opal SM, Sevransky JE, Sprung CL, Douglas IS, Jaeschke R, Osborn TM, Nunnally ME, Townsend SR, Reinhart K, Kleinpell RM, Angus DC, Deutschman CS, Machado FR, Rubenfeld GD, Webb S, Beale RJ, Vincent JL, Moreno R; Surviving Sepsis Campaign Guidelines Committee including The Pediatric Subgroup: Surviving Sepsis Campaign: international guidelines for management of severe sepsis and septic shock, 2012. Intensive Care Med 2013, 39:165-228

28. Stockman LJ, Bellamy R, Garner P: SARS: systematic review of treatment effects. PLoS Med 2006, 3:e343

29. Zhang Y, Sun W, Svendsen ER, Tang S, MacIntyre RC, Yang P, Zhang D, Wang Q: Do corticosteroids reduce the mortality of influenza A (H1N1) infection? A meta-analysis. Crit Care 2015, 19:46

30. World Health Organization: Clinical management of severe acute respiratory infection when Middle East respiratory syndrome coronavirus (MERS-CoV) infection is suspected. Interim Guidance 2 July 2015. Available at: http://www.who.int/csr/disease/coronavirus_infections/casemanagement-ipc/en 